\title{
Unveiling the Complex Configurational Landscape of the Intralayer Cavities in a Crystalline Carbon Nitride
}

\author{
Magnus Pauly, ${ }^{a}$ Julia Kröger, ${ }^{b}$ Viola Duppel, ${ }^{b}$ Corban Murphey, ${ }^{c}$ James Cahoon, ${ }^{c}$ Bettina V. \\ Lotsch, ${ }^{b,{ }^{*}}$ and Paul A. Maggard ${ }^{a,{ }^{*}}$ \\ a Department of Chemistry, North Carolina State University, Raleigh NC, 27695. \\ ${ }^{b}$ Max Planck Institute for Solid State Research, Stuttgart, Germany, 70569. \\ ${ }^{c}$ Department of Chemistry, University of North Carolina at Chapel Hill, Chapel Hill, NC 27599.
}

\begin{abstract}
The in-depth understanding of the reported photoelectrochemical properties of the layered carbon nitride, poly(triazine imide)/LiCl $(\mathrm{PTI} / \mathrm{LiCl})$, has been limited by the apparent disorder of the $\mathrm{Li} / \mathrm{H}$ atoms within its framework. To understand and resolve the current structural ambiguities, an optimized one-step flux synthesis $\left(470^{\circ} \mathrm{C}, 36 \mathrm{~h}, \mathrm{LiCl} / \mathrm{KCl}\right.$ flux $)$ was used to prepare $\mathrm{PTI} / \mathrm{LiCl}$ and deuterated-PTI/LiCl in high purity. Its structure was characterized by a combination of neutron/X-ray diffraction and transmission electron microscopy. The range of possible $\mathrm{Li} / \mathrm{H}$ atomic configurations were enumerated for the first time and, combined with total energy calculations, reveals a more complex energetic landscape than previously considered. Experimental data were fitted against all possible structural models, exhibiting the most consistency with a new orthorhombic model (Sp. Grp. Ama2) that also has the lowest total energy. In addition, a new $\mathrm{Cu}(\mathrm{I})$-containing $\mathrm{PTI}(\mathrm{PTI} / \mathrm{CuCl})$ was prepared with the more strongly scattering $\mathrm{Cu}(\mathrm{I})$ cations in place of $\mathrm{Li}$, and which also most closely matched with the partially-disorded structure in $\mathrm{Cmc2}_{1}$. Thus, a complex configurational landscape of PTI is revealed to consist of a number of ordered crystalline structures that are new potential synthetic targets, such as with the use of metal-exchange reactions.
\end{abstract}




\section{Introduction.}

Carbon nitrides have been the subject of intense recent investigations as semiconducting catalysts, such as for solar energy conversion. ${ }^{1-5}$ Generally, this class of materials includes covalent polymers based upon triazine and heptazine monomers forming a backbone consisting of strictly alternating carbon and nitrogen atoms (carrying $\mathrm{NH}_{x}$ moieties, but no $\mathrm{C}-\mathrm{H}$ bonds). Advantages of carbon nitrides include their lower cost, ease of synthesis and functionalization, low toxicity, as well as their greater kinetic stability as compared to most inorganic semiconductors. Their structures are typically layered, with the occurrence of intralayer cavities that can host solvent molecules, functional groups, and/or coordination sites for metal cations. The arrays of micropores typically embedded within covalent $\mathrm{CN}_{\mathrm{x}}$ frameworks thus represent a complex configurational landscape that can impact their physical properties. This feature has typically not been well characterized nor explored in carbon nitrides.

While structural characterization of most carbon nitrides is hindered by their partially amorphous character, a crystalline carbon nitride has been discovered in recent years, poly(triazine imide)/LiCl (i.e,. PTI/LiCl). $\mathrm{PTI} / \mathrm{LiCl}$ has garnered intense interest for its photocatalytic activity and utility in solar energy conversion. This includes as a photocatalyst for the reduction of water to dihydrogen, ${ }^{6-11}$ and/or for the oxidation of water to dioxygen when its surface is loaded with a Pt and/or $\mathrm{CoO}_{x}$ co-catalyst. ${ }^{7}$ It has also been investigated as a photocatalyst for the degradation of organic dyes in wastewater, ${ }^{12}$ and for use as a counter electrode in dye-sensitized solar cells. ${ }^{13}$ Notably, these reports include conflicting values for its band gap (2.95 to $3.15 \mathrm{eV}$ ), band energies and other photocatalytic properties.

Despite the well-defined carbon nitride substructure of $\mathrm{PTI} / \mathrm{LiCl}$, its intralayer cavities accommodate $\mathrm{Li} / \mathrm{H}$ atoms (Figure 1a) that have yielded conflicting reports regarding their ordered or disordered nature. The ' $\mathrm{C}_{6} \mathrm{~N}_{9}$ ' subcomponent of $\mathrm{PTI}$ was first characterized as exhibiting a hexagonal-based structure in space group $\mathrm{P} 6_{3} \mathrm{~cm} .{ }^{14}$ While this model is consistent with a 
complete disordering of the $\mathrm{Li} / \mathrm{H}$ atoms within its cavities, subsequent investigations have revealed evidence for the occurrence of partial ordering in the orthorhombic space group $\mathrm{Cmc} 2_{1}$ or a complete ordering in $\mathrm{P} 212121 .{ }^{15,16} \mathrm{~A}$ clear resolution of the $\mathrm{Li} / \mathrm{H}$ atoms is obscured by the

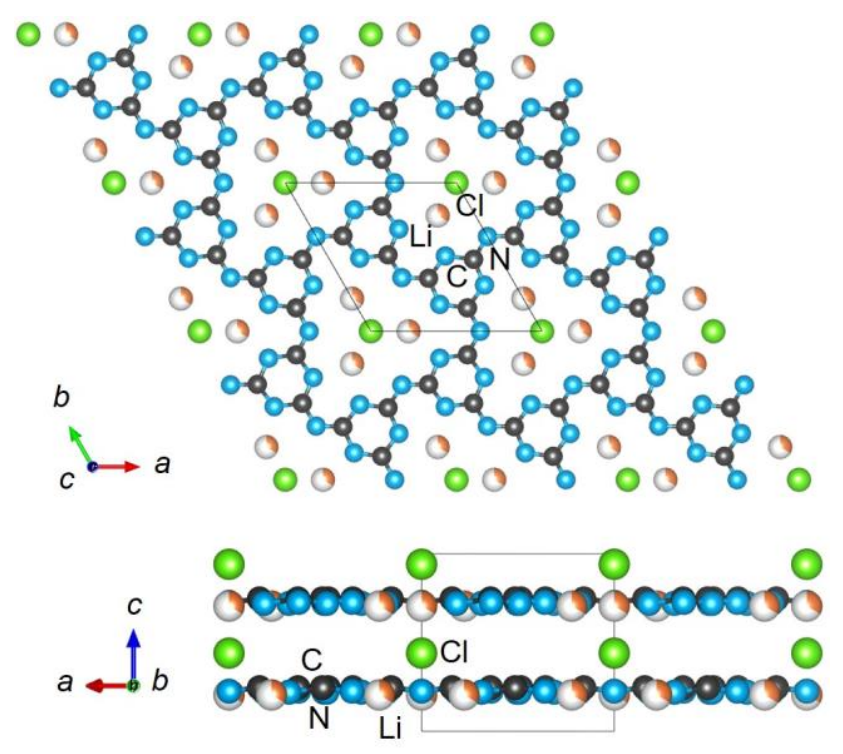

Figure 1. The crystalline structure of PTI $\left(\mathrm{C}_{6} \mathrm{~N}_{9} \mathrm{H}_{2} \mathrm{Li}{ }_{2} \mathrm{Cl}\right)$ in space group $\mathrm{P} 6_{3} \mathrm{~cm}$, showing the disordered intralayer cavities (upper) containing $\mathrm{Li} / \mathrm{H}$ atoms, and view along the layers (lower). weak X-ray scattering of these ions, as well as complicated by the high sensitivity of the crystallinity with reaction conditions. ${ }^{17}$ The latter is suggestive of a number of possible structural configurations, including both ordered and disordered, that is the possible origin of the seemingly differing structure reports and variances in its physical properties. $^{18}$ The full extent of alternate possible structural configurations has yet to be considered.

Presented herein is a complete enumeration of all potential structural models in the configurational landscape of $\mathrm{Li} / \mathrm{H}$ atoms within the $\mathrm{PTI} / \mathrm{LiCl}$ intralayer cavities and their relative total energies calculated by density-functional theory methods. These structural models have each been experimentally fitted against electron microscopy and X-ray and neutron diffraction data for $\mathrm{PTI} / \mathrm{LiCl}, d-\mathrm{PTI} / \mathrm{LiCl}$ (i.e., deuterated) and $\mathrm{PTI} / \mathrm{CuCl}$. The latter contains the more strongly scattering $\mathrm{Cu}(\mathrm{I})$ in partial replacement of $\mathrm{Li}(\mathrm{I})$ cations. A single-step synthesis of $\mathrm{PTI} / \mathrm{LiCl}$ in highcrystallinity was targeted in which melamine was reacted in a eutectic $\mathrm{LiCl} / \mathrm{KCl}$ flux in a molar ratio of 5:1 (melamine: flux) at a temperature of $470{ }^{\circ} \mathrm{C}$ for $36 \mathrm{~h}$ and cooled at a rate of $2{ }^{\circ} \mathrm{C} / \mathrm{h}$ within a sealed, evacuated fused-silica tube. To prepare $d-\mathrm{PTI} / \mathrm{LiCl}$, the protons in melamine were exchanged by $\mathrm{D}_{2} \mathrm{O}$ soaking prior to the flux synthesis. The use of a eutectic $\mathrm{LiCl} / \mathrm{KCl}$ flux in the synthesis enables the crystallization of $\mathrm{PTI} / \mathrm{LiCl}$, which has been posited to result from the stabilization of small molecule intermediates by the Li cation. ${ }^{17}$ Reaction conditions are thus 
critical, with both single step and multi-step reaction pathways reported to typically result in a wide possible range of crystallinity. The $\mathrm{PTI} / \mathrm{CuCl}$ was prepared by reacting $\mathrm{PTI}$ with $\mathrm{CuCl}$ in a molar ratio of 1.2:1 (CuCl:PTI molar ratio) at a temperature of $450^{\circ} \mathrm{C}$ for $24 \mathrm{~h}$ within a sealed, evacuated fused-silica tube. All products were washed multiple times in deionized water and then collected by centrifugation.

The crystalline structure of $\mathrm{PTI} / \mathrm{LiCl}$ in the highest-symmetry hexagonal system is plotted in Figure 1, as found in its first reported crystalline structure. ${ }^{14}$ Generally, its crystal structure contains triazine-rings fused together by imide functional groups. These layers are stacked and held together by the chloride anions located above and below the intralayer cavities, Figure 1 (lower). It has the composition $\left[\left(\mathrm{C}_{3} \mathrm{~N}_{3}\right)_{2}\left(\mathrm{NH}_{x} \mathrm{Li} \mathrm{i}_{1-x}\right)_{3} \cdot \mathrm{LiCl}\right.$, in which $\mathrm{C}_{3} \mathrm{~N}_{3}$ represents the triazine species and $\mathrm{NH}_{x} \mathrm{Li}_{1-x}$ the imide bridging groups. Elemental analysis of the $\mathrm{PTI} / \mathrm{LiCl}$ product gives $x=2 / 3$, and a nominal formula of $\mathrm{C}_{6} \mathrm{~N}_{9} \mathrm{H}_{2} \mathrm{Li}_{2} \mathrm{Cl}$ that is in line with prior studies that have shown partial deprotonation of the $\mathrm{NH}$ groups under similar reaction conditions. ${ }^{14-16}$

For this hexagonal symmetry, two protons and two lithium cations are each disordered over three symmetryequivalent coordination sites in the intralayer cavities, shown in Figure 1

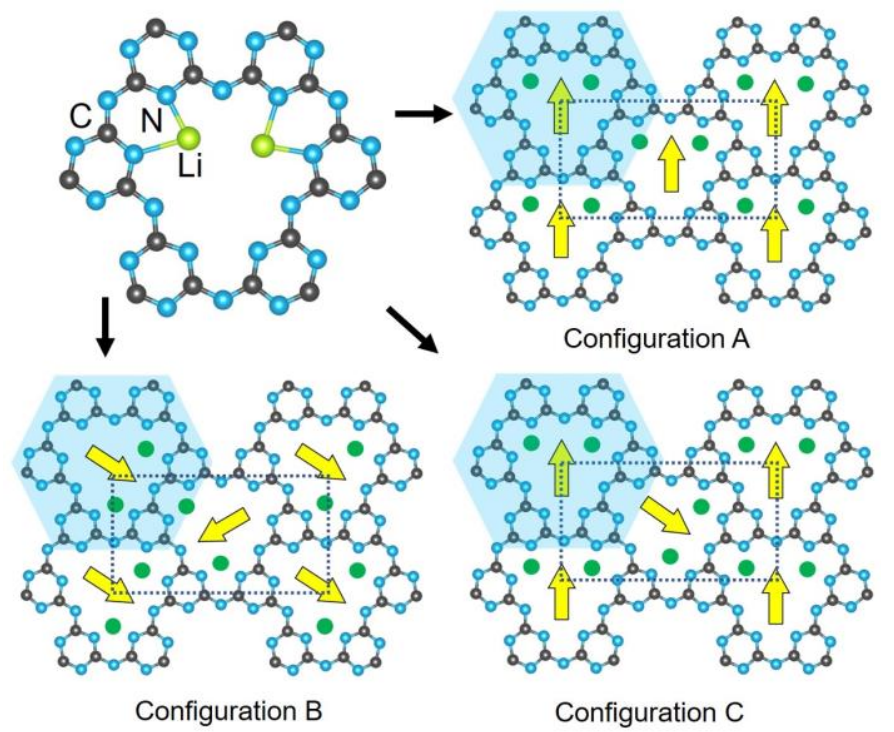

Figure 2. The Li-cation coordination within a cavity (upper), and different orientations between the cavities in the plane of the layer labelled as the configurations A, B, and C. Yellow arrows indicate the side of coordinated Li cations within the cavity, and atoms are labelled for C (black), N (blue), and Li (green). (upper). The alternative ordered structural models were fully enumerated according to three criteria, i.e., the coordination patterns of the i) lithium cations, ii) hydrogen atoms, and iii) layer-tolayer orientation of the $\mathrm{Li} / \mathrm{H}$ atoms. These ordered configurations were constructed from a metrically orthorhombic unit cell that derives from the hexagonal unit cell, as described 
previously, ${ }^{15,16,19}$ and which is indexable to the powder X-ray diffraction data (described below). This unit cell provides for two symmetry-unique intralayer cavities within the unit cell and leading to three possible Li-cation configurations, Figure 2. Each of these configurations contain two Li cations per intralayer cavity that are coordinated to $2 / 3$ of the chelating triazine groups. Additionally, two $\mathrm{H}$ atoms are contained within each cavity, and which can coordinate to either the $\mathrm{N}$-triazine or $\mathrm{N}$-imide groups that are opposite to the Li cations in the cavities. From one layer to the next, the orientation of the coordinated $\mathrm{Li} / \mathrm{H}$ atoms can be rotated by either $180^{\circ}$ or $60^{\circ}$. Representative examples of the different types of ordered structural configurations are provided in the Supplementary Information, Figure S4-S8. Total electronic energies for all structural models

Table 1. Ordered structural models for PTI/LiCl including were calculated for the geometry-relaxed structural details and calculated relative energies. The three lowest energy models are highlighted (red).

\begin{tabular}{|c|c|c|c|c|c|c|}
\hline $\begin{array}{c}\text { Class }^{1} \\
\text { (Li) }\end{array}$ & $\begin{array}{l}\text { Space } \\
\text { Group }\end{array}$ & $\begin{array}{c}\text { Rotate } \\
\left({ }^{\circ}\right)\end{array}$ & $\begin{array}{c}\mathrm{H} \text { on } \\
\mathrm{N}- \\
\text { imide }\end{array}$ & $\begin{array}{c}\mathrm{H} \text { on } \\
\mathrm{N}- \\
\text { triazine }\end{array}$ & $\begin{array}{c}\text { Relative } \\
\text { Energy } \\
(\text { eV/f.u. })^{2}\end{array}$ & $\begin{array}{l}\mathrm{Li} \cdots \mathrm{H} \\
(\%)^{3}\end{array}$ \\
\hline A1 & Ama2 & 60 & 2 & 0 & 0.932 & 100 \\
\hline A1a & Ama2 & 60 & 1 & 1 & 0 & 50 \\
\hline A1b & Pma2 & 60 & 1 & 1 & 0.157 & 50 \\
\hline $\mathrm{A} 2$ & $\mathrm{Cmcm}$ & 180 & 2 & 0 & 1.097 & 100 \\
\hline A2a & Pnma & 180 & 1 & 1 & 0.076 & 50 \\
\hline$A 2 b$ & $P 2_{1} / m$ & 180 & 1 & 1 & 0.134 & 50 \\
\hline $\mathrm{B} 1$ & $\mathrm{Pbcm}$ & 60 & 2 & 0 & 0.605 & 50 \\
\hline B1a & $\mathrm{Pbcm}$ & 60 & 1 & 1 & 1.941 & 0 \\
\hline B1b & $\mathrm{Pbcm}$ & 60 & 1 & 1 & 0.322 & 50 \\
\hline B2 & Pnma & 180 & 2 & 0 & 0.883 & 50 \\
\hline B2a & Pnma & 180 & 1 & 1 & 0.290 & 50 \\
\hline$B 2 b$ & Pnma & 180 & 1 & 1 & 1.383 & 0 \\
\hline $\mathrm{C} 1$ & $\mathrm{P} 21 / m$ & 60 & 2 & 0 & 0.816 & 75 \\
\hline C1a & $\mathrm{P} 2_{1} / \mathrm{m}$ & 60 & 1 & 1 & 0.126 & 50 \\
\hline $\mathrm{C} 1 \mathrm{~b}$ & $\mathrm{P} 21 / m$ & 60 & 1 & 1 & 0.807 & 25 \\
\hline $\mathrm{C} 2$ & $\mathrm{P} 21 / m$ & 180 & 2 & 0 & 1.331 & 75 \\
\hline $\mathrm{C} 2 \mathrm{a}$ & $\mathrm{P} 2_{1} / m$ & 180 & 1 & 1 & 0.284 & 50 \\
\hline $\mathrm{c} 2 \mathrm{~b}$ & $\mathrm{P} 2_{1} / \mathrm{m}$ & 180 & 1 & 1 & 0.668 & 25 \\
\hline
\end{tabular}

${ }^{1}$ Class of Li orientation with reference to Figure 1 , with $\mathrm{A}$ and $\mathrm{B}$ groups indicating the pattern of $\mathrm{H}$-atoms bonded to $\mathrm{N}$-imide groups.

${ }^{2}$ All energies are relative to $-603.123 \mathrm{eV}$ calculated for the A1a model.

${ }^{3}$ Percent of Li cations across from a protonated imide bridge. structures using density functional theory in VASP, ${ }^{20,21}$ using the generalized gradient approximation of Perdew, Burke and Ernzerhof. ${ }^{22}$ A k-point mesh of $4 \times 4 \times 2$ was used and dispersion force corrections were included within the DFT-D3(BJ) scheme and Becke-Johnson damping. ${ }^{23,24}$

Listed in Table 1, the enumeration of all ordered structural configurations using the above procedures resulted in 18 different crystalline structures exhibiting a minimum symmetry of monoclinic. The space group of each structural model, inclusive of the hydrogen atoms, was determined using PLATON and transformed to the standard unit cell settings and atomic coordinates within VESTA. ${ }^{25,26}$ This resulted in six different structural models for each of the configurations in Figure $2(\mathrm{~A}, \mathrm{~B}$ and $\mathrm{C}) .{ }^{27}$ Configuration $\mathrm{A}$ exhibits the highest space group 
symmetries (e.g., Cmcm, Ama2) with a single symmetry-unique cavity with all Li cations aligned identically within the pores, while configurations B and C yielded lower symmetries (e.g., Pbcm,

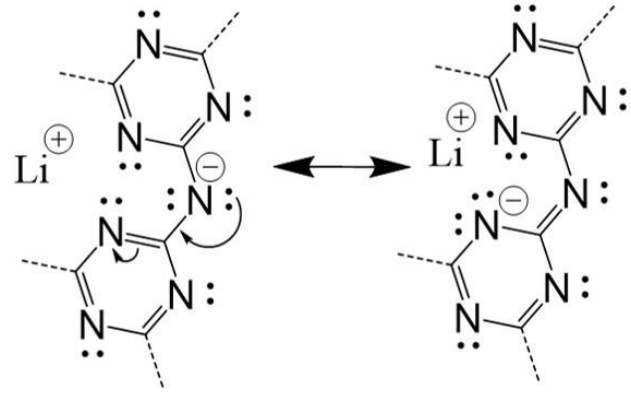

Scheme 1. Two resonance structures for a deprotonated imide bridge, including formal charges. Alternative resonance structures locate the formal charge on other $\mathrm{N}$-triazine groups near to Li cations in this and neighboring cavities.
$\left.\mathrm{P} 2{ }_{1} / m\right)$ and have two symmetryinequivalent cavities. The crystallographic information files of all structures are included in the Supplementary Information.

A few important trends between the structural features and the total electronic energies are evident. For example, there is

a significant decrease in electronic energy as one $\mathrm{H}$ atom per cavity is shifted from bonding an $\mathrm{N}$-imide to an $\mathrm{N}$-triazine group, i.e., in Table 1 compare $\mathrm{A} 1$ with $\mathrm{A} 1 \mathrm{a}$ and $\mathrm{A} 1 \mathrm{~b}$, or $\mathrm{A} 2$ with $\mathrm{A} 2 \mathrm{a}$ and A2b. The lowered energy with deprotonation of half of the imide bridges occurs for most of the related models and is partly related to the stabilization of the resonance structures which place the formal charge closer to the Li cations in the cavity, as shown in Scheme 1. In Table 1 this corresponds to the $\mathrm{Li} \cdots \mathrm{H}$ column, which gives the percentage of $\mathrm{Li}$ atoms across from protonated imide bridges, resulting in a lower electronic energies for lower percentages. This effect also couples to the $\mathrm{H}$-tautomerism (not shown), wherein a shift of a $\mathrm{H}$ atoms to the $\mathrm{N}$-triazine groups also leads to a shift of the electron density to nearby Li cations. Shown in Figure 3 are the geometry relaxed

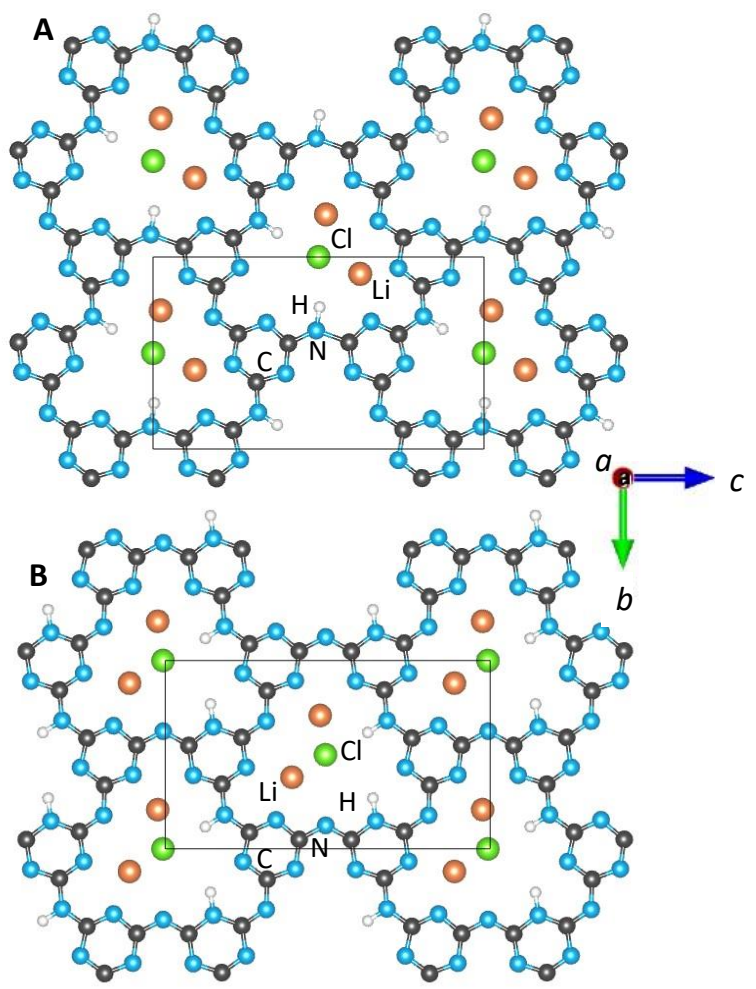

Figure 3. Crystalline structures of ordered PTI/LiCl models for $\mathrm{A} 1$ (A) and the lowest energy A1a (B) in the Ama2 space group for each. Atoms are labelled for $\mathrm{C}$ (black), N (blue), Li (orange), $\mathrm{Cl}$ (green) and $\mathrm{H}$ (white). 
structural models for $\mathrm{A} 1$ ( $\mathrm{H}$ on $\mathrm{N}$-imides only) and the lowest energy $\mathrm{A} 1 \mathrm{a}(\mathrm{H}$ on $\mathrm{N}$-imide and $\mathrm{N}$ triazine). Displacement of the $\mathrm{H}$ atoms from the $\mathrm{N}$-triazine to $\mathrm{N}$-imide groups can only result in a minimum of $50 \% \mathrm{Li} \cdots \mathrm{H}$ in category $\mathrm{A}$. However, in category $\mathrm{C}$ the $\mathrm{Li} \cdots \mathrm{H}$ decreases to $25 \%$, but which also has a larger number of close contacts between adjacent layers.

The A2a and $\mathrm{C} 1 \mathrm{a}$ models in Pnma and $\mathrm{P}_{2} / \mathrm{m}$ constitute the second and third lowest relative electronic energies compared to $\mathrm{A} 1 \mathrm{a}$, with all three in red font in Table 1. The model in Pnma is consistent with the previously reported $\mathrm{Li} / \mathrm{H}$ ordering model within the lower-symmetry (non-isomorphic) subgroup of $\mathrm{P} 2{ }_{1}{ }_{2}{ }_{2}{ }_{1}$. However, the energetic differences between the lowestenergy structural models must be considered to be relatively small as compared to the experimental range of synthesizability for carbon nitrides $\left(\sim 0.2 \mathrm{eV}\right.$ atom ${ }^{-1}$ above the ground state). ${ }^{28}$ Thus, the experimentally-observed crystallization of different ordered or disordered $\mathrm{PTI} / \mathrm{LiCl}$ structures, with only small changes in reaction conditions, is very likely owing to the fact that the nucleation of carbon nitrides is strongly kinetically-driven. The conflicting structures reported in the literature may only reflect the dependence of the $\mathrm{Li} / \mathrm{H}$ ordering on the synthetic conditions. For example, higher temperatures and subsequent quenching lead to less welldefined Bragg diffraction peaks.

Rietveld refinements of the $\mathrm{PTI} / \mathrm{LiCl}$ powder XRD based on the structural models all gave similarly good fits owing to the weak scattering of the $\mathrm{Li} / \mathrm{H}$ atoms. To better probe the $\mathrm{Li} / \mathrm{H}$ ordered structures, neutron diffraction data were taken on a deuterated-PTI/LiCl $(d-\mathrm{PTI} / \mathrm{LiCl})$ that was prepared using reaction conditions that yielded the highest crystallinity. The deuterium exchange was confirmed by peak shifting present in the FTIR data in Figure S2 (Supplementary Information). Rietveld refinements for $d-\mathrm{PTI} / \mathrm{LiCl}$ were performed for each of the ordered structure models in Table 1. The best fit was observed for the lowest-energy A1a model in Ama2, plotted in Figure 4, as judged by the weighted residual and the absence of additional diffraction peaks predicted by the other models in Table 1. For example, as a result of different ordering of the $\mathrm{Li} / \mathrm{H}$ positions in alternative models, additional (non-observed) diffraction peaks were predicted at $d$ - 


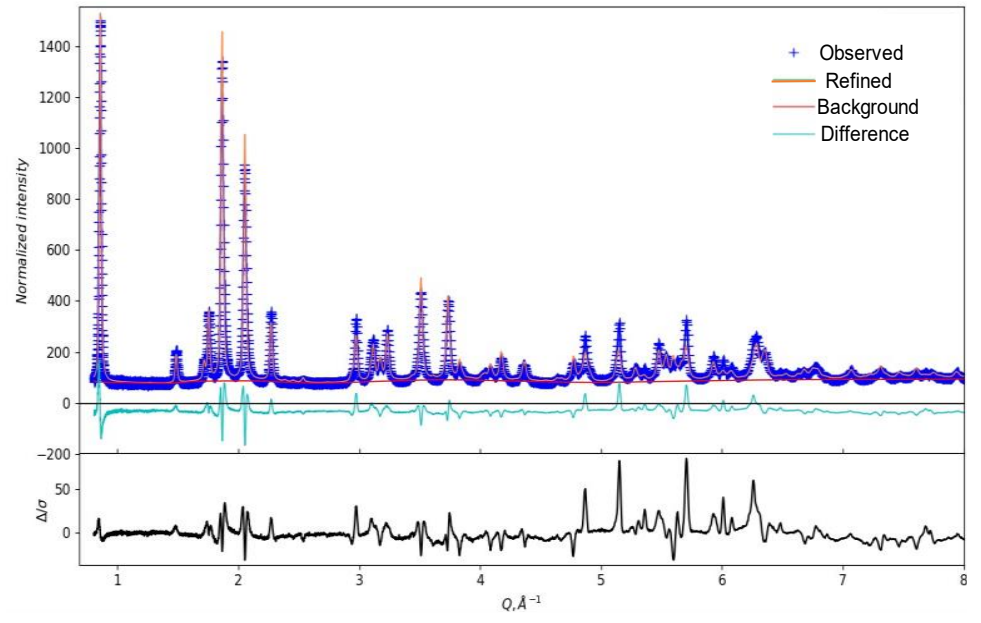

Figure 4. Results of Rietveld refinement of neutron diffraction data for $d$ $\mathrm{PTI} / \mathrm{LiCl}$ in space group Ama2 (A1a model; wR\% $=7.5 ; a=6.7336(2) \AA, b=$ $8.452(2) \AA$, and $c=14.625(3) \AA)$. spacings of $\sim 4.5 \AA$ for $\mathrm{A} 1 \mathrm{~b}, \mathrm{~A} 2$, and $\mathrm{A} 2 \mathrm{a}$, or at $\sim 5.5 \AA$ for $\mathrm{C} 1 \mathrm{a}, \mathrm{C} 2$ and C2a. The A1a model only exhibited peaks which could be indexed by the structure model in the neutron diffraction pattern. However, similarly low refinement residuals of $\sim 7$ to $8 \%$ were found for all models, except for the disordered phases $\mathrm{Cmc2}{ }_{1}$ and $\mathrm{P} 6_{3} \mathrm{~cm}$ which yielded

larger residuals of $>10 \%$.

To introduce the more strongly scattering $\mathrm{Cu}(\mathrm{I})$ cation in the cavities of $\mathrm{PTI} / \mathrm{LiCl}$, i.e., to prepare $\mathrm{PTI} / \mathrm{CuCl}$, flux exchange reactions were performed according to Reaction 1:

$$
\mathrm{CuCl}+\mathrm{KCl}+\mathrm{C}_{6} \mathrm{~N}_{9} \mathrm{H}_{2} \mathrm{Li}_{2} \mathrm{Cl} \rightarrow x \mathrm{LiCl}+(1-x) \mathrm{CuCl}+\mathrm{KCl}+\mathrm{C}_{6} \mathrm{~N}_{9} \mathrm{H}_{2} \mathrm{Li}_{2-x} \mathrm{Cu}_{x} \mathrm{Cl}
$$

The addition of $\mathrm{KCl}$ to the mixture lowers its melting point, and the salt products are subsequently removed by washing in aqueous solution. The reaction is thermodynamically driven by the more negative heat of formation of $\mathrm{LiCl}$ versus $\mathrm{CuCl}$ (i.e., $-408 \mathrm{~kJ} \mathrm{~mol}^{-1}$ versus $-138 \mathrm{~kJ} \mathrm{~mol}^{-}$ ${ }^{1}$, respectively). It is also driven by the greater enthalpy of $\mathrm{N}$-ligand binding of $\mathrm{Li}$ versus $\mathrm{Cu}$ (e.g., $\mathrm{M}(\mathrm{I})$-pyridine of $-180 \mathrm{~kJ} \mathrm{~mol}^{-1}$ and $-260 \mathrm{~kJ} \mathrm{~mol}^{-1}$ for $\mathrm{M}=\mathrm{Li}$ and product contains up to $32.5 \mathrm{~mol} \%$ $\mathrm{Cu}(\mathrm{I})$ cations and maintains the PTI structure by powder XRD. A higher concentration of the $\mathrm{Cu}(\mathrm{I})$ cation can be introduced, but this results in a new crystalline phase of PTI/CuCl that is currently under investigation.

Powder XRD refinements were performed on the PTI/CuCl product using the structural models in Table 1, with the partial replacement of $\mathrm{Cu}$ for $\mathrm{Li}$ cations in the cavities. The best fits were obtained for the A1a (Ama2), B1 (Pbcm) and B2 (Pnma) structural models, with weighted 
refinement residuals of $6.6 \%, 7.2 \%$ and $7.3 \%$, respectively. The $\mathrm{Cu}(\mathrm{I})$-content of $\mathrm{C}_{6} \mathrm{~N}_{9} \mathrm{H}_{2} \mathrm{Li}_{2-x} \mathrm{Cu}_{x} \mathrm{Cl}$ refined consistently across all models, giving $x=0.65(1), 0.65(2)$ and $0.65(2)$, respectively. Alternative structural models resulted in additional (non-observed) peaks in the simulated diffraction patterns and relatively larger weighted residuals. The partially disordered model $\mathrm{Cmc}{ }_{1}$ resulted in low weighted residual of $\sim 6.0 \%$ and $x=0.68(2)$. Additional refinement details are provided in the Supplementary Information.

HRTEM images and electron diffraction data were also taken on $\mathrm{PTI} / \mathrm{CuCl}$ in order to better distinguish between the possible structure models. Images of some of the selected crystallites that were relatively small and thin are shown in Figure 5 and given in Figure S12. The in-plane layer is clearly shown in the hexagonally-shaped crystallite and is homogeneous. The view down the [100] direction of the stacking of layers is shown in Figure $5 \mathrm{~b}$ and exhibits few detectable stacking faults. The carbon nitride substructure is thus preserved after the $\mathrm{Cu}(\mathrm{I})$ exchange reactions, as is also corroborated by FTIR and PXRD data, given in the Supplementary Information. From the selected area electron diffraction, the structural models $\mathrm{B} 1(\mathrm{Pbcm})$ and $\mathrm{B} 2$ (Pnma) could be excluded from

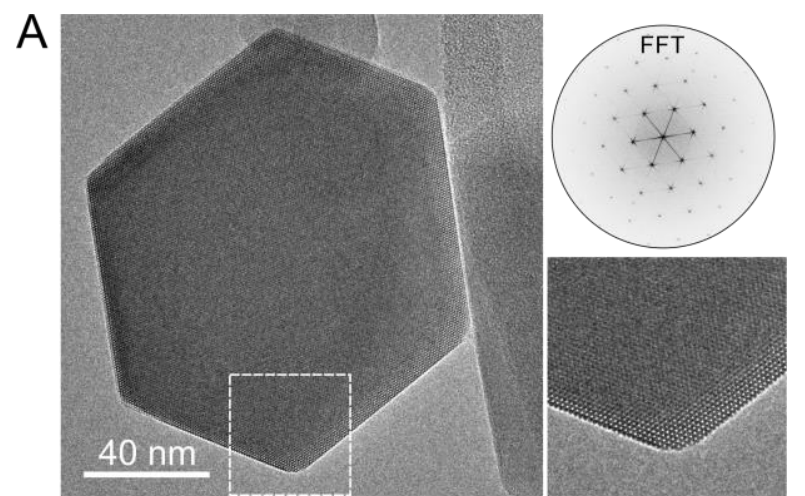

B

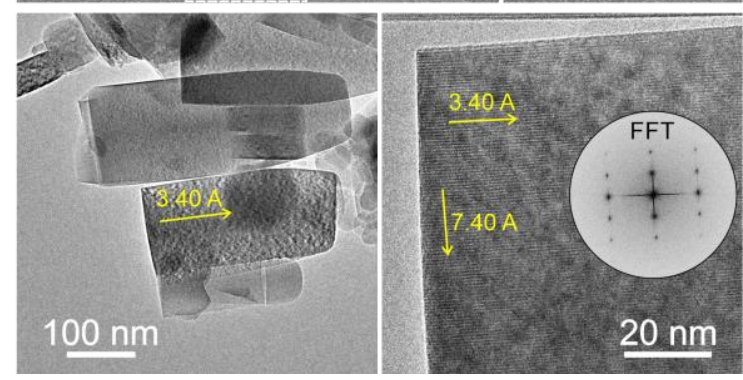

Figure 5. HRTEM images of PTI/CuCl viewed down the [001] (a) and the [100] zone axis (b) with the interlayer (7.40 $\AA$ ) and intercavity spacings ( $3.40 \AA$ ) labeled with yellow arrows. consideration based upon the observed intensity distribution down the [110] and [011] zone axes, Figure S11. The two remaining models found to be most consistent with the selected area electron diffraction were the ordered $\mathrm{A} 1 \mathrm{a}$ (Ama2) and the partially $\mathrm{H} / \mathrm{Li}$-disordered structure previously reported in $\mathrm{Cmc} 2{ }_{1}{ }^{15}$ 
Rietveld refinements of the XRD data according to the two above models showed consistently better fits and peak matching to the latter, partially $\mathrm{H} / \mathrm{Li}$-disordered, $\mathrm{Cmc2}{ }_{1}$ structural model. This structure shows the closest consistency with the fully ordered A2 model $(\mathrm{C} \mathrm{mcm})$ in terms of the interlayer and intralayer $\mathrm{Li}$ arrangements (i.e., category $\mathrm{A}$ and $180^{\circ}$ layer orientation in Table 1). However, this model is also $>1.0 \mathrm{eV} / \mathrm{f}$.u. higher than the lowest energy structure, Table 1, owing to the fact that the $\mathrm{H}$ atoms are bonded only to the $\mathrm{N}$-imide groups. Using
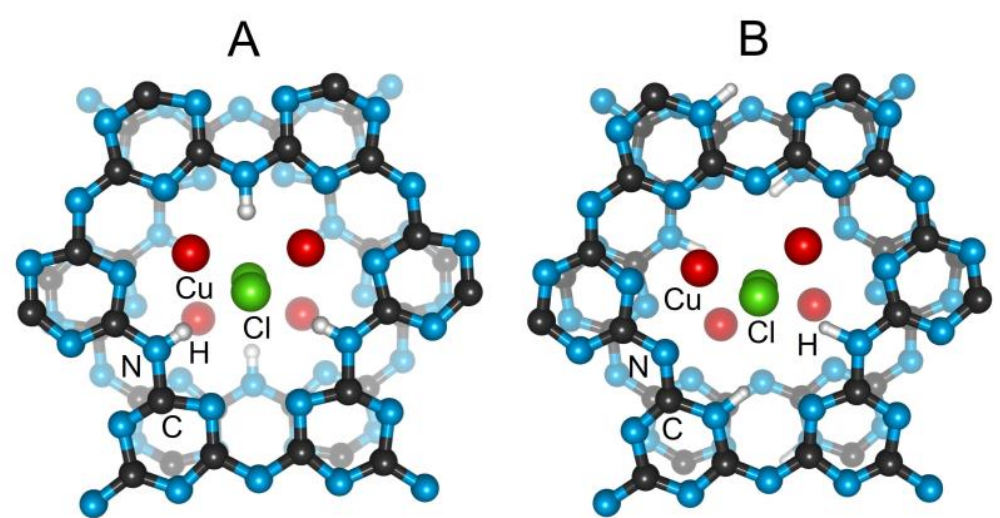

Figure 6. Crystalline structures of $\mathrm{PTI} / \mathrm{CuCl}$ in the partially-disordered model in $\mathrm{Cmc2}_{1}(\mathrm{~A} ; \mathrm{H}$ sites are only partially occupied) and the fully ordered A2a model in Pnma (B; $\mathrm{H}$ sites are fully occupied). This illustrates the only significant difference between them is the disordered $\mathrm{H}$-atom positions in the former. Atoms are labelled for C (black), $\mathrm{N}$ (blue), Li (green), $\mathrm{Cl}$ (green), $\mathrm{Cu}$ (red), and $\mathrm{H}$ (white). synchrotron X-ray data, ${ }^{15}$ it was

noted that the structure refinements were insensitive to the $\mathrm{H}$-atom positions. The refined structure of $\mathrm{PTI} / \mathrm{CuCl}$ in $\mathrm{Cmc2}_{1}$ thus likely corresponds instead to a partially-disordered structural model derived from shifting $50 \%$ of the $\mathrm{H}$ atoms in $\mathrm{A} 2(\mathrm{Cmcm})$ to

the N-triazine groups, e.g., to A2a (Pnma). Shown in Figure 6 is a comparison of the structural models in $\mathrm{Cmc2}_{1}$ and Pnma. The models are basically the same within and between the intralayer cavities, except for a disordering of the $\mathrm{H}$-atom positions and a slight shifting of the metal-cation positions. It should also be noted that the $\mathrm{P} 2{ }_{1} 2_{1} 2_{1}$ model is also consistent with these structures after some subtle $\mathrm{Cl}$-atom shifting that causes further symmetry breaking.

Thus, while evidence for an ordered structure is found for $d-\mathrm{PTI} / \mathrm{LiCl}$ in A1a (Ama2) that corresponds to the lowest energy model, the flux exchange reaction has caused a partial disordering of the intralayer cavities in $\mathrm{PTI} / \mathrm{CuCl}$. A complete disorder of the metal/H atoms within the cavities would eventually yield the highest-symmetry $\mathrm{P} 6_{3} \mathrm{~cm}$ structure as described in the original structural report. ${ }^{14}$ Given the number of competing low energy structures in Table 1, a disordered structure could easily arise with the use of slightly more harsh reaction conditions (e.g., 
higher temperatures and reaction quenching) that tend to favor a higher degree of disorder. The configurational entropy will favor disordered structural arrangements at higher temperatures. For example, preliminary evidence for the complete disorder of intralayer cavities has recently been found with the exchange of divalent metal cations into the structure, e.g., in $\mathrm{PTI} / \mathrm{ZnCl}$, which is currently under investigation.

Conclusions. The intralayer cavities within the crystalline $\mathrm{PTI} / \mathrm{LiCl}$ have been found to provide a complex configuration landscape for metal cations and $\mathrm{H}$ atoms. Starting from a metrically orthorhombic unit cell, the arrangements of $\mathrm{Li} / \mathrm{H}$ within its cavities results in 18 distinct structural models that maintained a minimum of monoclinic symmetry. Total energy calculations revealed that the lowest energy models possessed structural features which included, i) displacement of $\mathrm{H}$ atoms from the $\mathrm{N}$-imide to $\mathrm{N}$-triazine groups, ii) $\mathrm{Li}$ coordination to triazine groups that have a deprotonated $\mathrm{N}$-imide bridge, and iii) the fewest number of interlayer $\mathrm{Li} \cdots \mathrm{H}$ interactions. Refinements of the structural models against neutron diffraction data of $d-\mathrm{PTI} / \mathrm{LiCl}$ gave a best fit to the new, lowest-energy structural model A1a in space group Ama2. While both this structure and its synthesis is different from prior literature, the presence of other similarly lowenergy structures also likely leads to a strong dependence of its crystalline structure on the reaction conditions. The partial replacement of monovalent $\mathrm{Li}$ for $\mathrm{Cu}$ cations using flux-based reactions, giving $\mathrm{PTI} / \mathrm{CuCl}$, which was best matched to the partially disordered structure in $\mathrm{Cmc2}_{1}$. Finally, the elucidation of the range of possible structural $\mathrm{Li} / \mathrm{H}$ arrangements in $\mathrm{PTI} / \mathrm{LiCl}$ can be used to analyse and more fully understand the reported range of photoelectrochemical and photocatalytic properties for this class of crystalline carbon nitrides in the future.

Conflicts of interest. There are no conflicts of interest to declare. 
Acknowledgments. This work was primarily supported by the Center for Hybrid Approaches in Solar Energy to Liquid Fuels (CHASE), an Energy Innovation Hub funded by the U.S. Department of Energy, Office of Science, Office of Basic Energy Sciences under Award Number DE-SC0021173, supporting M.P., J.C. and P.M. for the synthetic work and the structural modeling and calculations. A portion of this research also used resources at the POWGEN Powder Diffractometer at Beamline 11A for structural characterization of the deuterated PTI/LICI that was sent to the Spallation Neutron Source, a DOE Office of Science User Facility operated by the Oak Ridge National Laboratory. HRTEM data and images were collected at the Max Planck Institute (B.L., J.K., V.D.), with acknowledgment of infrastructure support for these studies by the Cluster of Excellence e-conversion (EXC 2089) and the Center for Nanoscience (CeNS).

\section{References.}

1) T. Banerjee, F. Podjaski, J. Kröger, B.P.Biswal, B.V. Lotsch, Nat. Rev. Mater., 2021, 6, 168190.

2) L. Lin, Z. Yu, X. Wang, Angew. Chem. Int. Ed. 2019, 58, 6164-6175.

3) S. Cao, J. Low, J. Yu, M. Jaroniec, Adv. Mater. 2015, 27, 2150-2176.

4) V. Briega-Martos, A. Ferre-Vilaplana, A. de la Peña, J.L. Segura, F. Zamora, J.M. Feliu, E. Herrero, ACS Catal. 2017, 7, 1015-1024.

5) J. Zhu, P. Xiao, H. Li, S.A.C. Carabineiro, ACS Appl. Mater. Interfac. 2014, 6, 16449-16465.

6) K. Schwinghammer, M.B. Mesch, V. Duppel, C. Ziegler, J. Senker, B.V. Lotsch, J. Am. Chem. Soc. 2014, 136, 1730-1733.

7) Y. Ham, K. Maeda, D. Cha, K. Takanabe, Chem. - An Asian J., 2013, 8, 218-224.

8) L. Lin, C. Wang, W. Ren, H. Ou, Y. Zhang, X. Wang, Chem. Sci., 2017, 8, 5506-5511.

9) L. Heymann, S.C. Bittinger, C. Klinke, ACS Omega, 2018, 3, 17042-17048.

10) K. Schwinghammer, B. Tuffy, M.B. Mesch, E. Wirnhier, C. Martineau, F. Taulelle, W. Schnick, J. Senker, B.V. Lotsch, Angew. Chem. Int. Ed. 2013, 52, 2435-2439.

11) Y. Huang, M. Su, Y. Zhou, D. Chen, Z. Xu, H. Zhang, C. Liao, Ceram. Int., 2020, 46, $26492-$ 26501. 
12) L. Tian, J. Li, F. Liang, J. Wang, S. Li, H. Zhang, S. Zhang, Appl. Catal. B: Env. 2018, 225, 307-313.

13) W. Lee, Y.-S. Jun, J. Park, G.D. Stucky, J. Mater. Chem. A, 2015, 3, 24232-24236.

14) E. Wirinhier, M. Döblinger, D. Gunzelmann, J. Senker, B. Lotsch, W. Schnick, Chem. Eur. J. 2011, 17, 3213-3221.

15) C.-Z. Liao, V. W-hei Lau, M. Su, S. Ma, C. Liu, C.-K. Chang, H.-S. Sheu, J. Zhang, K. Shih, Inorg. Chem. 2019, 58, 15880-15888.

16) M.B. Mesch, K. Bärwinkel, Y. Krysiak, C. Martineau, F. Taulelle, R.B. Neder, U. Kolb, J. Senker, Chem. Eur. J. 2016, 22, 16878-16890.

17) F.K. Kessler, W. Schnick, Zeitsch. Anorg. Allg. Chem. 2019, 645, 857-862.

18) L. Lin, Z. Lin, J. Zhang, X. Cai, W. Lin, Z. Yu, X. Wang, Nat. Catal. 2020, 3, 649-655.

19) J. Wang, D. Hao, J. Ye, N. Umezawa, Chem. Mater. 2017, 29, 2694-2707.

20) G. Kresse, J. Furthmüller, Phys. Rev. B: Condens. Matter. 1996, 54, 11169-11186.

21) G. Kresse, J. Furthmüller, Comput. Mater. Sci., 1996, 6, 15-50.

22) J.P. Perdew, K. Burke, M. Ernzerhof, Phys. Rev. Lett., 1996, 77, 3865-3868.

23) S. Grimme, J. Antony, S. Ehrlich, S. Krieg, J. Chem. Phys. 2010, 132, 154104.

24) S. Grimme, S. Ehrlich, L. Goerigk, J. Comput. Chem. 2011, 32, 1456.

25) A.J. Spek, PLATON. A Multipurpose Crystallographic Tool, 2002, Utrecht University, The Netherlands. (http://www.platonsoft.nl/platon/)

26) K. Momma, F. Izumi, J. Appl. Crystallogr 2011, 44, 1272-1276.

(https://jp-minerals.org/vesta/en/)

27) It should be noted that helical arrangements of the Li/H positions were also modelled and resulted in similar electronic energies as compared to the nonhelical arrangements. This required a tripling of the cell dimension perpendicular to the layers, as illustrated for one example in the Supporting Information in Figure S10.

28) W. Sun, S.T. Dacek, S.P. Ong, G. Hautier, A. Jain, W.D. Richards, A.C. Gamst, K.A. Persson, G. Ceder, Sci. Adv. 2016, 2, e1600225(1-8).

29) N.S. Rannulu, M.T. Rodgers, J. Phys. Chem. A 2007, 111, 3465-3479.

30) M.T. Rodgers, P.B. Armentrout, Mass Spect. Rev. 2000, 19, 215-247. 